\title{
Desfazendo os nós heteronormativos da escola: contribuições dos estudos culturais e dos movimentos LGBTT'
}

Raquel Pinho"

Rachel Pulcino"II

I- Este artigo é o resultado do desenvolvimento do trabalho Movimentos LGBTTT e educação: os nós heteronormativos do pensamento e da escola, apresentado no IV Simpósio Internacional de Educação Sexual: feminismos, identidades de gênero e políticas públicas, realizado na Universidade Estadual de Maringá (UEM), em abril de 2015.

II- Pontifícia Universidade Católica do Rio de Janeiro, Rio de Janeiro, RJ, Brasil.

Contato: raquel.aps@gmail.com

III- Pontifícia Universidade Católica do Rio de Janeiro, Rio de Janeiro, RJ, Brasil. Contato: rachelpulcino@gmail.com

IV- Elegemos a sigla LGBTTT para indicar os movimentos de Lésbicas, Gays, Bissexuais, Travestis, Transexuais e Transgêneros. Entendemos que há muitas combinações desses termos no esforço de representar as diferenças sexuais e de gênero. No entanto, acreditamos que nenhuma combinação dá conta da diversidade de identidades que habitam esses movimentos

\section{Resumo}

0 trabalho a seguir configura-se como uma pesquisa de caráter teórico, que tem por objetivos compreender as noções de cultura e identidade e, a partir delas e de reflexões a respeito da história e da atuação dos movimentos LGBTTT ${ }^{\mathrm{IV}}$, ponderar possibilidades de superação de práticas escolares heteronormativas. Primeiro, expõe considerações a respeito do conceito de cultura, o que inclui uma explanação acerca dos diferentes tipos de multiculturalismo. Em seguida, articula os conceitos de cultura e identidade, a partir dos quais se destacam os processos de reconhecimento e de representação, fazendo alguns apontamentos sobre igualdade e diferença. Depois, reflete especificamente a respeito das identidades sexuais e as contribuições das estruturas sociais que modelam tais identidades sem, no entanto, as determinarem. A partir disso, enfoca os movimentos LGBTTT como movimentos de ressignificação e resistência das práticas heteronormativas. E, por fim, conclui indicando o pensamento intercultural crítico e pós-moderno como aquele que pode repensar e desconstruir os mecanismos de exclusão das diferenças sexuais presentes no cotidiano escolar. Mas, também, como aquele que pode resgatar a problematização para o espaço escolar, constituindo-o como espaço de discussão, onde as verdades são abaladas. Trata-se do local onde é possível pensar, refletir e se colocar no lugar do outro. Um espaço no qual é possivel ser diferente.

\section{Palavras-chave}

Identidade - Sexualidade - Movimentos LGBT Multiculturalimo - Educação intercultural. 


\section{Undoing the heteronormative tangles of school: contributions of cultural studies and LGBTTT movements'}

Raquel Pinho"

Rachel Pulcino"II

I- This article has resulted from of the work Movimentos LGBTTT e Educação: os nós heteronormativos do pensamento $e$ da escola [The LGBTTT and education: the heteronormative tangles of thought and school, presented at IV Simpósio Internacional de Educação Sexual: feminismos, identidades de gênero e políticas públicas [IV Sexual Education International Symposium: feminisms, gender identity and public policy], held at Universidade Estadual de Maringá (UEM), in April 2015.

II- Pontifícia Universidade Católica do Rio de Janeiro, Rio de Janeiro, RJ, Brasil.

Contact: raquel.aps@gmail.com

III- Pontifícia Universidade Católica do Rio de Janeiro, Rio de Janeiro, RJ, Brasil. Contact: rachelpulcino@gmail.com

IV- LGBTTT stands for the movements of the Lesbian, Gay, Bisexual, Transvestite, Transsexual, and Transgender. We understand that there are many combinations of these terms in an effort to represent sexual and gender differences. However, we believe that no combination comprises the diversity of identities present in these movements.

\section{Abstract}

This study is a theoretical research that has sought to understand the concepts of culture and identity and, from these and reflections on the history and the proceeding of the LGBTTT ${ }^{I V}$ movements, ponder on possibilities of overcoming heteronormative school practices. First, it presents considerations on the concept of culture, which includes an explanation of the different types of multiculturalism. Then, it articulates the concepts of culture and identity, whereupon the processes of recognition and representation are highlighted, and brings some notes on equality and difference. After, it reflects specifically on the sexual identities and contributions of social structures that shape such identities without, however, determining them. From this, it focuses on LGBTTT movements as movements to resignify and resist to heteronormative practices. Finally, it concludes that the critical and postmodern intercultural thinking is one that can not only rethink and deconstruct the mechanisms of exclusion of sexual differences present in everyday school life, but also reclaim the questioning for school space, making it a forum for discussion, where truths are shaken. Where it is possible to think, reflect on and put oneself in the other's place. A space in which it is possible to be different.

\section{Keywords}

Identity - Sexuality - LGBT Movements - Multiculturalism Intercultural education. 


\section{Cultura e diversidade}

cultura - Cultura é o conjunto acumulado de símbolos, ideias e produtos materiais associados a um sistema social, seja ele uma sociedade inteira ou uma família. [...] A cultura possui aspectos materiais e não materiais. A cultura material inclui tudo o que é feito, modelado ou transformado como parte da vida social coletiva, da preparação do alimento à produção de aço e computadores, passando pelo paisagismo que produz jardins do campo inglês. A cultura não material inclui símbolos - de palavras à notação musical -, bem como as ideias que modelam e informam a vida de seres humanos em relações recíprocas e os sistemas sociais dos quais participam. As mais importantes dessas ideais são as atitudes, as crenças, os valores e as normas (JOHNSON ${ }^{1}$, Allan, 1997, p. 59, grifos do autor).

cultura (lat. cultura) 3. Em oposição à natura (natureza), a cultura possui duplo sentido antropológico: a) é o conjunto das representações e dos comportamentos adquiridos pelo homem enquanto ser social. Em outras palavras, é o conjunto histórica e geograficamente definido das instituições características de determinada sociedade, designando "não somente as tradições artísticas, científicas, religiosas e filosóficas de uma sociedade, mas também suas técnicas próprias, seus costumes políticos e os mil usos que caracterizam a vida cotidiana" (Margaret Mead); b) é o processo dinâmico de socialização pelo qual todos esses fatos de cultura se comunicam e se impõem em determinada sociedade, seja pelos processos educacionais propriamente ditos, seja pela difusão das informações em grande escala, a todas as estruturas sociais,

1- Referenciar autores com nome e sobrenome e não apenas sobrenome como feito usualmente é uma forma de evidenciar os gêneros dos pesquisadores e, por consequência, as mulheres na pesquisa, o que contribui com as lutas de reconhecimento e com valorização da identidade feminina de forma mais ampla. mediante os meios de comunicações de massa. Nesse sentido, cultura praticamente se identifica com o modo de vida de uma população determinada, vale dizer, com todo o conjunto de regras e comportamentos pelos quais as instituições adquirem um significado para os agentes sociais (JAPIASSÚ, Hilton; MARCONDES, Danilo, 2006, p. 63, grifos dos autores).

Em alinhamento com o acima citado, Stuart Hall (2001, p. 32) define cultura como o terreno real de práticas, representações e costumes de qualquer grupo histórico específico. Para ele, a cultura não tem um caráter fixo. Ao contrário, ela é fluida, coletiva e produtiva. Fluida, uma vez que as produções humanas estão constantemente se redescobrindo e se reinventando. Coletiva, porque é produzida e reproduzida através de relações entre pessoas, ou seja, de relações sociais. E produtiva, por suas ações e efeitos, isto é, refere-se àquilo que nós fazemos com a cultura, e também àquilo que a cultura faz conosco. Mas isso não implica reduzir tudo à cultura, não implica argumentar que nada existe senão a cultura. Na verdade, implica considerar que em toda prática social se encontram envolvidas questões de significado cultural.

Povos isolados apresentam culturas bem demarcadas. Neles, ritos e rituais específicos são passados às novas gerações e compõem a tradição cultural. As emoções e os comportamentos, treinados desde a mais terna idade, determinam personalidades específicas. A coletividade atua mais para manter e transmitir os hábitos culturais tradicionais do que para atualizá-los de acordo com novos quereres, fazeres e saberes. Tais formas de transmissão cultural variam de acordo com cada cultura e são fundamentais para a manutenção das sociedades.

0 objetivo da transmissão cultural é ensinar a pensar, atuar e sentir adequadamente (SPINDLER, George, 1987, p. 206). Contudo, o processo de transmissão cultural não é 
necessariamente racional, o que demonstra sua naturalização. No processo de naturalização, reside a tomada de todos esses aspectos culturais, tanto materiais quanto não materiais, como verdades, como a forma certa de realização e de pensamento.

Com o aumento da globalização e do contato entre culturas, manter tais tradições blindadas de interferência externa é um grande desafio para os povos. Inseridas no mesmo espaço social, diversas culturas historicamente estabelecidas são obrigadas a conviver, não apenas as culturas, mas também todos os seus significados, suas verdades e suas formas de transmissão cultural. É nesse momento que os conflitos emergem e vemos uma disputa acirrada de poder. Segundo Michel Foucault (2000, p. 12), saber e poder estão estritamente relacionados. Para ele, não existe verdade absoluta, mas:

[...] cada sociedade tem seu regime de verdade, sua "política geral" de verdade: isto é, os tipos de discurso que ela acolhe e faz funcionar como verdadeiros; os mecanismos e as instâncias que permitem distinguir os enunciados verdadeiros dos falsos, a maneira como se sanciona uns e outros; as técnicas e os procedimentos que são valorizados para a obtenção da verdade; o estatuto daqueles que têm o encargo de dizer o que funciona como verdadeiro.

Assim, um discurso acolhido como culturalmente verdadeiro, além de julgar e classificar, atua desqualificando e excluindo outros discursos e, com isso, reforça a sua hegemonia de discurso universal. Nas relações sociais, aquele que se constitui no discurso dominante, e com isso na verdade estabelecida, detém o poder em comparação ao outro, desprovido desta verdade.

0 discurso, a verdade e o poder são construídos na relação, que se estabelece entre as pessoas, sem que ninguém seja detentor (FOUCAULT, Michel, 2009, p.104), ou seja, o poder não possui materialidade, ele é relacional. Enquanto existe relação, existe o poder. Fora da relação, não há poder. Contudo, muitas vezes ouvimos e dizemos que um determinado grupo possui o poder ou que existe "assimetria de poder entre os diferentes grupos socioculturais" (CANDAU, Vera, 2009, p. 52). Mas não devemos pensar o poder como algo material que um determinado grupo sociocultural possui, e sim que nas diversas relações sociais estabelecidas um determinado grupo sociocultural recorrentemente detém o poder. Lembramos ainda que tais relações não acontecem sem disputa e sem conflito.

A sociedade contemporânea brasileira abarca uma diversidade de grupos socioculturais. Apesar disso, é preciso ter cuidado ao afirmar sua multiculturalidade, uma vez que multicultural e pluricultural possuem significados diferentes. Segundo, Alan Johnson (1997, p. 52), o pluralismo cultural é o fenômeno de coexistência de diferentes culturas que mantêm certo grau de identidade separada, ou seja, não renuncia inteiramente à sua origem. Em contrapartida, mais que um fenômeno, o multiculturalismo é um movimento ativo nascido nos Estados Unidos que objetiva a valorização de meios formativos étnicos diferentes (JOHNSON, Alan, 1997, p. 155). A respeito do multiculturalismo, Vera Candau (2012, p. 242-243) explica-nos que:

[...] a palavra multiculturalismo é polissêmica, admitindo pluralidade de significados. [...] No entanto, é possivel reduzir a diversidade de sentidos atribuídos ao termo multiculturalismo a três fundamentais, que denomino multiculturalismo assimilacionista, multiculturalismo diferencialista e multiculturalismo interativo.

\section{0 multiculturalismo assimilacionista} busca a integração de todos à sociedade e a incorporação de todos à cultura hegemônica, mas sem modificar a matriz estrutural da sociedade. No caso da educação, promove-se uma política de universalização da escolarização, mas sem 
questionar seu caráter monocultural. Quanto ao multiculturalismo diferencialista, este coloca ênfase no reconhecimento da diferença e nas garantias de expressão e participação das diferentes identidades culturais presentes na sociedade, pois visa a manter as matrizes culturais. Já o multiculturalismo interativo ou interculturalidade articula políticas de igualdade com políticas de identidade e reconhecimento das diferenças. Em alinhamento com a autora, acreditamos ser o terceiro tipo o mais adequado para a construção de sociedades democráticas.

Indo além, a autora aponta a existência de três diferentes concepções de multiculturalismo interativo: relacional, funcional e crítica (CANDAU, 2012, p. 243244). 0 multiculturalismo interativo relacional refere-se basicamente ao intercâmbio entre culturas e sujeitos socioculturais. Esta concepção tende a reduzir as relações interculturais a interpessoais. 0 multiculturalismo interativo funcional é assumido como uma estratégia política dos governos para favorecer a coesão social, assimilando os grupos socioculturais subalternizados à cultura hegemônica, ou seja, também não afeta a estrutura e as relações de poder vigentes. Já o multiculturalismo interativo crítico ou interculturalidade critica vai questionar as desigualdades construídas ao longo da história entre diferentes grupos socioculturais, inclusive as de gênero e sexualidade. Assim, tal perspectiva aponta à construção de sociedades que assumam as diferenças como constitutivas da democracia e que sejam capazes de construir relações novas, verdadeiramente igualitárias, entre os diferentes grupos socioculturais, o que supõe empoderar aqueles que foram historicamente inferiorizados.

Um grupo sociocultural é um sistema social que envolve interação regular entre seus membros e uma identidade coletiva comum (JOHNSON, Allan, 1997, p. 118). Isso significa que o grupo tem um senso de nós que permite que seus membros se considerem como pertencendo a uma entidade separada e superior a eles. Dessa forma, existe uma separação bem marcada: nós - os pertencentes ao grupo - e eles
- os que estão de fora do grupo. Essa sensação de pertencimento delimita uma identidade, o que gera hostilidades às fronteiras e conflitos a partir das diferenças.

\section{Identidade}

De uma perspectiva sociológica, o self é um conjunto relativamente estável de percepções sobre quem somos em relação a nós mesmos, aos outros e aos sistemas sociais. [...] Em um nível mais estrutural o self baseia-se também em ideias culturais sobre os status sociais que ocupamos. Dessa maneira, por exemplo, a mulher que é mãe recorrerá a ideias culturais sobre mães ao construir sua ideia sobre quem ela é. De modo análogo, ela pode usar ideias culturais sobre mulheres, sobre várias ocupações, sobre idade e assim por diante, e com elas formar um senso geral sobre quem ela é. Este componente do autoconceito, que se baseia nos status sociais ocupados pelo indivíduo, é conhecido como identidade social (grifos do autor, JOHNSON, Allan, 1997, p. 126, 204).

identidade (lat. tardio identitas) 4. A questão da identidade e da diferença, do mesmo e do outro, é uma das questões mais centrais da metafísica clássica em seu surgimento (Heráclito, Parmênides, Platão). Temos, por um lado, a busca de um elemento único, a essência, o ser, que explique a totalidade do real (Parmênides); por outro lado, o pluralismo de Heráclito vê o real como reino da diferença, da mudança e do conflito, sendo que em um sentido dialético algo pode ser e não ser o mesmo, já que está em mudança. Platão busca, de certo modo, conciliar ambas as posições que o influenciaram em sua metafísica dualista, segundo a qual a mudança pertence ao mundo material, ao mundo das aparências, sendo o mundo das formas fixo, eterno (JAPIASSÚ, Hilton; MARCONDES, Danilo, 2006, p. 145). 
No início do século XX, a antropologia concretizou-se como a disciplina que conhecemos hoje a partir do desenvolvimento de quatro importantes linhas acadêmicas: Franz Boas, Radcliffe-Brown, Bronislaw Malinowski e Marcel Mauss (ERIKSEN, Thomas, 1995, p. 13). Basicamente, estas linhas afirmam a centralidade dos processos culturais para a consolidação da diversidade de identidades encontradas no mundo. Ou seja, a observação das diferentes culturas leva-nos à observação das diferenças entre elas e aponta-nos que as características humanas não são completamente naturais, mas naturalizadas, oriundas de processos sociais e disputas históricas de construção de características dominantes.

A cultura produz sentidos e significados. Esses sentidos estão contidos em estórias, memórias e imagens que servem de referências e nexos para a constituição das identidades. Os indivíduos com suas identidades serão responsáveis pela perpetuação dos elementos culturais, isto é, pela transmissão cultural. Vemos, então, que as identidades e a cultura, à qual elas pertencem, se retroalimentam, sendo ambas fluidas e em processo. Elementos culturais dão forma às identidades. Enquanto que cada indivíduo é um agente de reprodução e modificação dos elementos da cultura.

A identidade abarca um conjunto de identidades transculturais, uma vez que possuímos identidades sexuais, de gênero, étnicas, religiosas, econômica etc. Zilá Bernd (2005, p. 149) afirma que o prefixo trans comporta as noções de ultrapassagem, de passar além, de sair de si mesmo, e gera novas formas de conhecimento e de relação com o mundo. Entendemos identidades transculturais como aquelas que perpassam as culturas, por exemplo: mesmo que em cada cultura os signos e significados das identidades de gênero sejam diferentes, todas as culturas possuem identidades de gênero. Entretanto, apesar de ser multidimensional, a identidade não perde sua unidade, uma vez que cada indivíduo irá integrar uma pluralidade de referências e marcadores identitários em seu eu. A identidade é única, mas também fragmentada. As identidades transculturais não apenas coexistem; elas influenciam umas nas outras, se entrecruzam. Como veremos adiante, as identidades sexuais e de gênero estão fortemente relacionadas e se influenciam mutuamente. Por exemplo, ser heterossexual implica a relação com o gênero oposto. Muitas vezes, assumir uma identidade sexual implica assumir um gênero e vice-versa. Mas o que acontece quando se transgride essa relação gênero-sexualidade?

Como dito anteriormente, para além de um conjunto de características, a identidade envolve o sentimento de integração a um grupo de pertencimento, o que é influenciado pelos mecanismos de afiliação e exclusão, isto é, por processos de identificação ou estranhamento, pela demarcação simbólica de quem pode ou não pertencer ao grupo, pela definição do nós e do eles, o que nos leva à representação, ao processo como o outro é representado e ao processo de como eu sou representado a partir do outro. Assim, ser mulher implica não ser homem e implica negar todas as características que compõem a identidade masculina. Stuart Hall (2000, p. 110) afirma que:

[...] as identidades são construídas por meio da diferença e não fora dela. Isso implica o reconhecimento radicalmente perturbador de que é apenas por meio da relação com o outro, da relação com aquilo que não é, com precisamente aquilo que falta, com aquilo que tem sido chamado de exterior constitutivo, que o significado "positivo" de qualquer termo - e, assim, sua "identidade" - pode ser construído.

Sendo a construção da identidade um processo relacional e contínuo, e admitindo sua incompletude, seria melhor falarmos em identificação no lugar de identidade, pois ela nos dá a ideia de uma relação entre indivíduos e práticas discursivas. A identificação apontanos o reconhecimento de uma característica 
comum, mas também o seu caráter processual, de algo que está sendo, é transitório e vai se modificando de acordo com as experiências e os encontros.

Dito isso, corroboramos com uma visão subjetivista do fenômeno da identidade. Denys Cuche (2002, p. 180) aponta-nos que existem duas formas de pensar a identidade. A concepção objetivista define e descreve a identidade a partir de um certo número de critérios determinantes e objetivos: a origem comum, a língua, a cultura, a religião, o território etc. Já a concepção subjetivista encara a identidade como um fenômeno dinâmico, um sentimento de vinculação ou uma identificação a uma coletividade imaginária. No entanto, apontamos que é necessário cuidado para não interpretar a identidade como um processo efêmero baseado em escolhas racionais. A coletividade existe, resiste e exerce forte influência na identificação, a partir de mecanismos explícitos e velados em discursos e práticas.

Allan Johnson (1997, p. 204) destaca que uma parte importante da identidade é o eu ideal, que consiste nas ideias de quem deveríamos ser. A partir da reflexão a respeito da expressão coletivos feitos desiguais, de Miguel Arroyo (2010, p. 1381), que nos força a ler na própria expressão os processos históricos de produção-reprodução dessas desigualdades sociais, preferimos utilizar não a ideia de um eu ideal, mas de um eu idealizado ou um eu feito ideal. Assim, colocamos em evidência o processo social e histórico de construçãoprodução desse ideal. Distintas representações identitárias podem circular no espaço social, mas apenas algumas delas ganham visibilidade, ou seja, negamos a diversidade e passamos a encarar as representações visibilizadas como sendo a realidade. Dessa forma, os grupos culturais ligados a essas representações são vistos como normais e têm a possibilidade de representar não só a si mesmos, como a todos os outros. Eles tornam-se a norma, a referência, o natural, o ideal. Contudo, esse processo não é imune a conflitos interpessoais, tampouco a conflitos intrapessoais, pois a comparação desta identidade idealizada com a identidade real pode afetar a autoestima, acarretando consequências negativas para o indivíduo.

Além do autorreconhecimento, temos o reconhecimento do outro, daquele ou daquela que não compartilha atributos que possuímos, e que acontece a partir do lugar social que ocupamos (LOURO, Guacira, 2010, p. 15). Nesse processo de reconhecimento identitário, está presente a atribuição de diferenças, mas também a instauração de desigualdades. 0 que temos presenciado a respeito das diferenças sexuais é que são hierarquizadas, instituindo desigualdades sexuais, a exemplo: as heterossexualidades se constituem como norma a partir da rotulação das outras práticas como desviantes, subversivas ou doentes.

Segundo Vera Candau (2012, p. 239),

[...] é possível se trabalhar questões relacionadas à igualdade sem incluir a questão da diferença, nem se pode abordar a questão da diferença dissociada da afırmação da igualdade. De fato, a igualdade não está oposta à diferença, e sim a desigualdade, e diferença não se opõe a igualdade e sim a padronização, a produção em série, a uniformização.

Isso significa que devemos desconstruir o conceito de igualdade que remete a um processo de uniformização, homogeneização e padronização, pois tal processo está orientado a afırmação de uma cultura comum a que todos e todas têm direito a ter acesso. Nele, as diferenças culturais não são reconhecidas; ao contrário, são silenciadas e negadas. Isso significa também desassociar o conceito de diferença de deficiência ou déficit cultural. E também destituí-lo de sinônimo da desigualdade. A desigualdade instaura-se sobre as diferenças, quando estas são hierarquizadas, ou seja, quando a uma diferença é atribuída o valor de normal, ficando outras com o rótulo de anormais, desviantes, inferiores. Reconhecer a articulação entre igualdade 
e diferença é lutar contra padronizações e desigualdades que marginalizam e excluem os indivíduos de importantes espaços de socialização, tais como a escola.

Sendo assim, as ideias reiteradas pela cultura e pelas instituições sociais influenciam no modo como os indivíduos encaram as diferenças e, consequentemente, constroem suas identidades. Dentro do objetivo deste texto, ressaltamos as diferenças sexuais. Sexualidade e gênero estão relacionados entre si e atrelados ao componente biológico do corpo, mas não somente. Sexualidade e gênero também possuem um caráter fortemente cultural. Não é apenas algo dado, mas um processo histórico e relacional, o que significa dizer que se constituem em meio a uma rede que envolve corpo, prazer, normas, proibições, fugas, saberes e poderes (FERRARI, Anderson, 2014, p. 114). A forma como a cultura apropria-se dos corpos define as práticas e os rituais relacionados ao sexo, o que impacta a construção social das identidades sexuais.

\section{Identidade sexual}

Ora, é evidente que essas identidades (sexuais e de gênero) estão profundamente inter-relacionadas; nossa linguagem e nossas práticas muito frequentemente as confundem, tornando difícil pensá-las distintamente. No entanto, elas não são a mesma coisa (LOURO, Guacira, 2008a, p. 26-27).

Para Maria Luiza Heilborn (1993, p. 51), gênero significa a dimensão dos atributos culturais conferidos a cada um dos sexos em contraste com a dimensão anatômicofisiológica dos seres humanos. Todavia, podemos ser mais precisos: conota a dimensão psicológica e cultural, inscrita nos corpos biológicos, construída historicamente, baseada nos estereótipos e padrões sexuais de feminino e masculino, que envolve relações de poder nas diversas instituições sociais. Indo além,
[...] podemos analisar gênero como uma sofisticada tecnologia social heteronormativa, operacionalizada pelas instituições médicas, linguísticas, domésticas, escolares e que produzem constantemente corpos-homens e corpos-mulheres. Uma das formas para se reproduzir a heterossexualidade consiste em cultivar os corpos em sexos diferentes, com aparências "naturais" e disposições sexuais diferentes. (BENTO, Berenice, 2006, p. 1).

$\mathrm{Na}$ sociedade brasileira, temos dois gêneros (mulher e homem) baseados em dois sexos (fêmea e macho), separados dicotomicamente de acordo com características sexuais primárias (aparelhos reprodutores) e secundárias (pelos, voz, forma do corpo, seios) distintas. Segundo Joan Scott (1995, p. 8586), as relações de gênero são constitutivas das relações sociais e nelas podemos encontrar mecanismos e formas de relações de poder, nas quais mulheres e homens são organizados dentro de um conjunto específico de características que definem padrões idealizados daquilo que conhecemos como feminino e masculino.

Embora esta distinção pareça-nos biologicamente óbvia, em outras culturas podemos observar um, três ou mais gêneros. Por exemplo, as hijras da Índia, Bangladesh e Paquistão são consideradas um terceiro gênero. As hijras podem ser indivíduos tanto pertencentes a uma casta quanto a um culto. Possuem uma deusa própria, Bahuchara Mata. Pela visão ocidental, podem ser consideradas mulheres transgênero ou transexuais, dependendo se foi ou não realizada a castração (remoção do pênis). Apesar de ter um passado participativo, após a ocupação britânica dessas regiões, esta casta é marginalizada e excluída de vários espaços sociais, sendo obrigada a viver escondida ou de mendicância e prostituição (KHALEELI, Homa, 2014).

A sexualidade é entendida aqui como um conjunto de vivências, práticas cotidianas, de usos e costumes associados à intimidade, 
ao prazer e às expressões amorosas. Ela está envolvida em valores morais e é influenciada por práticas, discursos e pensamentos coletivos (FURLANI, Jimena, 2007, p. 13). Apesar de existirem grupos culturais para a sexualidade, também chamados de orientação sexual, a identidade sexual é pessoal e construída durante o processo de vida do sujeito, isto é, a identidade sexual do indivíduo mantém características que o permitem pertencer a um grupo cultural, mas não se encerra em tais características básicas. Existem diversas formas de expressar e viver a heterossexualidade, assim como existem para todas as outras orientações sexuais. É por isso que damos preferência ao tratamento no plural das orientações: heterossexualidades, homossexualidades, bissexualidades, transexualidades e assexualidades.

Longe de surgir espontaneamente de cada corpo recém-nascido, a identidade sexual inscreve-se reiteradamente por meio de repetições e de recitações dos códigos socialmente investidos como naturais (BENTO, Berenice, 2006, p. 2). Assim, tidas como natural, as heterossexualidades constituem-se em uma matriz que conferirá sentido às diferenças entre os gêneros. Da mesma forma, a reiteração dos papéis de gênero garante o discurso das heterossexualidades. A esta ordem social naturalizada, chamamos heteronormatividade. Sendo assim, a sociedade em que vivemos pode ser classificada como heteronormativa. Podemos destacar cinco instituições sociais que atuam de forma significativa no controle heteronormativo por meio de discursos e práticas: a família, as religiões, as ciências médicas, as leis jurídicas e a escola (BORRILLO, Daniel, 2010, p. 41; FOUCAULT, Michel, 2009).

As ciências médicas, que voltaram seu olhar para as sexualidades a partir do século XVIII, esforçaram-se, em alinhamento com o pensamento judaico-cristão, para descobrir a origem das homossexualidades e como curá-la. Especialmente a psiquiatria localizou por muito tempo as homossexualidades nas categorias de doença, neurose, perversão e/ou excentricidade.
Até 17 de maio de 1990, as homossexualidades constavam na Classificação Internacional de Doenças (CID) da Organização Mundial de Saúde (OMS), quando foi oficialmente desmarcada como patologia. Todavia, ainda constam como doenças os transtornos de identidade sexual (Código F64), que contém os subitens transexualismo (F64.0) e travestismo bivalente (F64.1). A CID é usada largamente na Europa Ocidental e no Brasil, sendo referencial do nosso Sistema Único de Saúde (SUS). Já nos EUA, é adotado o Diagnostic and Statistical Manual of Mental Disorders (DSM) pela American Psychiatric Association (APA), no qual as homossexualidades não constam como doença desde 1973 e no qual as bissexualidades nunca foram classificadas como transtorno. Acerca dos indivíduos transgêneros, o documento aponta que alguns recebem o diagnóstico psiquiátrico de disforia ${ }^{2}$ de gênero quando procuram tratamento. Contudo ter tal diagnóstico, ou ser transgênero, ou ser gênero variante, não implica qualquer prejuízo no julgamento, estabilidade, confiabilidade ou capacidades gerais sociais e vocacionais, o que permite ter acesso aos direitos jurídicos como qualquer outro cidadão. Vale ressaltar que a APA se posiciona oficialmente contra qualquer tipo de discriminação a tais identidades e a favor da contemplação dessas identidades nos direitos jurídicos.

De modo geral, as religiões cristãs possuem uma tradição moral que condena o que é contrário à heterossexualidade, por transgredir aos papéis de gênero e, com isso, a vontade de Deus. Segundo o documento Sexualidade humana: verdade e significado, a Igreja Católica considera que "os atos de homossexualidade, que são intrinsecamente desordenados e contrários à lei natural" (VATICANO, 1995). 0 documento ainda reforça os papéis de gênero e indica a castidade pré-matrimônio e o matrimônio como os melhores caminhos para uma vida plena em

2- (1) Mal-estar, (2) Indisposição, (3) Mudança repentina e transitória do estado de ânimo, tais como sentimentos de tristeza, pena, angústia, (4) Antônimo de euforia. 
Deus. Além das homossexualidades, a Igreja condena explicitamente o que ela classifica como perversões sexuais: a masturbação, a fornicação, a prostituição, a pornografia, o estupro, o incesto e a pedofilia, entre outros. Esse conjunto é problemático, pois diferentes práticas são colocadas em pé de igualdade moral. Além disso, as religiões cristãs estão ainda fortemente atreladas ao Estado, apesar dos esforços em se constituir um Estado laico para além dos documentos oficiais.

As leis jurídicas não contemplam direitos fundamentais aos homossexuais. Um passo dado em direção à igualdade de direitos se deu em 05 de maio de 2011, quando foi reconhecida, por unanimidade pelo Superior Tribunal Eleitoral (STF), a união estável entre pessoas do mesmo sexo e pedida a procedência das ações para excluir qualquer significado do artigo 1.723 do Código Civil que impeça o reconhecimento da união entre pessoas do mesmo sexo como entidade familiar. Contudo, em 2013, o deputado Anderson Ferreira ${ }^{3}$ (PRPE) pediu aprovação do Projeto de Lei 6583/13, que cria o Estatuto da família, no qual o art. $2^{\circ}$ define entidade familiar como:

[...] o núcleo social formado a partir da união entre um homem e uma mulher, por meio de casamento ou união estável, ou ainda por comunidade formada por qualquer dos pais e seus descendentes.

Não obstante, a criação de tal estatuto é um retrocesso, pois marginaliza outras confıgurações de família, como: mãe solteira e filhos, pai solteiro e filhos, casais divorciados e filhos, casais heterossexuais que não possuem contratos matrimoniais, entre outras já presentes e legitimadas em nosso cotidiano. A criação do Estatuto da família deve ser pensada como um problema não só para as famílias de casais homossexuais, como também para as de casais heterossexuais.

3- Em seu perfil público, o deputado Anderson Ferreira declara-se evangélico.
A escola e a família reproduzem saberes sem considerar a base fortemente heteronormativa da nossa sociedade e atuam no controle e vigilância das identidades de gênero e sexualidade. Não obstante, é indispensável que reconheçamos que a escola não apenas reproduz as concepções de gênero e sexualidade que circulam na sociedade, mas que ela própria as produz. A escola tem sido uma das instituições sociais responsáveis pelo controle e a correção dos considerados anormais, dos desviantes, fazendo funcionar os dispositivos disciplinares de poder. Segundo Michel Foucault (2008, p. 117),

[...] a 'disciplina' não pode se identificar com uma instituição nem com um aparelho; ela é um tipo de poder, uma modalidade para exercê-lo, que comporta todo um conjunto de instrumentos, de técnicas, de procedimentos, de níveis de aplicação, de alvos; ela é uma 'física' ou uma 'anatomia' do poder, uma tecnologia.

A escola pratica a pedagogia da sexualidade e o disciplinamento dos corpos, que são sutis, velados, contínuos e, por isso, muito eficientes e duradouros (LOURO, Guacira, 2010, p. 17). Isso porque independe dos discursos explícitos, da existência de uma disciplina de educação sexual. A sexualidade está na escola porque ela faz parte dos sujeitos, ela não é algo que se possa desligar ou despir (LOURO, Guacira, 2008a, p. 81). Ao legitimar determinadas identidades e práticas sexuais, reprime e marginaliza outras. A produção das heterossexualidades é acompanhada pela rejeição das homossexualidades, que se expressa na homofobia declarada ou disfarçada.

Dessa forma, a escola é também um espaço de violência contra as identidades outras de gênero e sexualidade. Em contrapartida, por ser um espaço legitimado de verdade e saber, meninos e meninas buscam a escola como um espaço de entendimento para o que estão vivendo no campo das sexualidades, reforçando a escola como um lugar do conhecimento 
e vinculando diretamente a questão das sexualidades ao saber (FERRARI, Anderson, 2014, p. 107). 0 debate social em torno das sexualidades entra na escola sem pedir licença e os conflitos emergem, convocando-a a participar deste movimento de ressignificação.

0 que podemos constatar é que tais instituições sociais não funcionam isoladamente. Elas se permeiam e reforçamse, dando suporte ao funcionamento da outra. Também podemos notar uma grande resistência dos grupos dominantes aos avanços progressistas, não apenas evitando o avanço dos movimentos multiculturais, mas também tentando reverter processos já legitimados, como é o caso da tentativa de criação do Estatuto da familia. Ainda assim, dentro de cada uma dessas instituições existem diferentes correntes de pensamento e muitos avanços já foram realizados. Porém, apesar de tais ondas alternativas e lutas políticas por reconhecimento, a heteronormatividade ainda se encontra fortemente naturalizada.

\section{Contextualização dos movimentos LGBTTT ${ }^{4}$ no Brasil e no mundo}

Os Direitos Humanos proclamados pela Organização das Nações Unidas (ONU), em 1948, são fruto de uma longa trajetória histórica e estão relacionados com as lutas sociais. Primeiramente, as lutas se dão por referenciais da modernidade, ou seja, possuem as questões da igualdade, da liberdade e da universalidade como centrais em sua construção. Na modernidade, a preocupação era com a identificação nacional e com as lutas de classe. Estes são considerados movimentos sociais tradicionais.

A partir do fim da Segunda Guerra Mundial, vislumbramos um desenrolar pós-moderno, no qual o eterno passa a ser

4- Elegemos a sigla LGBTIT para indicar os movimentos de Lésbicas, Gays, Bissexuais, Travestis, Transexuais e Transgêneros. Entendemos que existam muitas combinações desses termos no esforço de representar as diferenças sexuais e de gênero. No entanto, acreditamos que nenhuma combinação dá conta da diversidade de identidades que habitam esses movimentos. contingente, o local se sobrepõe ao geral e os interesses se particularizam (ALVES, José Augusto, 2005, p. 32), pois o processo de identificação vai privilegiar a comunidade como espaço de realização individual. 0 espaço de disputas se amplia. As reivindicações por cidadania são apresentadas por grupos menores que o Estado e independentes das classes sociais, são os novos movimentos sociais: grupos raciais, movimentos LGBTTT, iniciativas feministas, representações religiosas, entre outros. Os novos movimentos sociais trouxeram em seus discursos a valorização de princípios como livre organização, autogestão, democracia de base, direito à diversidade e respeito à individualidade, respeito à identidade local e regional, e noção de liberdade individual associada à liberdade coletiva. Atualmente, os novos movimentos sociais questionam em que medida os direitos conquistados na modernidade reconhecem as diferenças culturais.

Esses novos eixos de radicalização dos princípios de igualdade e liberdade através da busca pelo respeito à diferença só foram conquistados por meio da militância que se organizou em torno das demandas de cada um desses segmentos e que politizou outros espaços da vida social. Segundo Marco Aurélio Prado; Frederico Machado (2008, p. 84), apesar dos movimentos e ações coletivas não totalizarem as frentes de participação em torno destas questões, eles foram fundamentais para processar os pontos mais visíveis dos impasses público e institucional junto ao Estado-nação.

A respeito dos movimentos LGBTTT no mundo ocidental, temos três momentos temporais bem demarcados. 0 primeiro momento refere-se ao surgimento e à manutenção de diversas organizações, em países europeus, do fim do século XVIII até o início do século XX. Um segundo momento refere-se ao pósguerra e termina no Stonewall Riots ${ }^{5}$, cuja fase demarca uma maior organização e uma ideologia orientada para o assimilacionismo

5- Para mais informações, ver: Marco Aurélio Prado; Frederico Machado, 2008, p. 99-100. 
social. 0 terceiro momento, chamado Liberação gay, começa em 1969 e se prolonga até hoje. Assistimos a uma volta radical do mundo gay no cenário social em uma ideologia orientada para o ativismo social, na qual esta minoria exerce cada vez mais influência na cultura, nas instituições e na política. É nessa fase que emerge uma heterogeneidade de termos para tentar dar conta das identidades homossexuais (PRADO, Marco Aurélio; MACHADO, Frederico, 2008, p. 88).

0 ativismo pró-valorização da diversidade sexual eleva as homossexualidades de um problema pessoal a um problema social. A discussão não se limita mais a processos de exclusão estruturais e passa a abranger processos de exclusão simbólica. Nos Estados Unidos, a participação política e as alianças com outros grupos identitários em prol de conquista de direitos aumentaram no início da década de 70, mas se enfraqueceram logo depois devido a disputas dentro e fora dos movimentos, por exemplo: em relação à constituição de uma representação identitária da homossexualidade na sociedade e à resistência encontrada nos grupos sociais conservadores, respectivamente. A notoriedade dos movimentos foi retomada na década de 80 com a proliferação dos casos de AIDS $^{6}$. Apesar de um primeiro momento de forte culpabilização das práticas homossexuais pela proliferação do vírus, e com isso o reforço do preconceito, os movimentos adquirem recursos materiais e estruturais para a sua manutenção.

Os movimentos LGBTTT norteamericanos influenciaram muitas frentes pelo mundo. No Brasil, foi criada em 31 de janeiro de 1995, com 31 grupos fundadores, a Associação Brasileira de Lésbicas, Gays, Bissexuais, Travestis e Transexuais (ABGLT), cuja missão é promover ações que garantam a cidadania e os direitos humanos de lésbicas, gays, bissexuais, travestis e transexuais, contribuindo para a

6- A Síndrome da Imunodeficiência Adquirida (SIDA, em inglês: AIDS) é provocada pelo Vírus da Imunodeficiência Humana (VIH, em inglês: HIV), que penetra no organismo por contato com uma pessoa infectada. A transmissão se dá por: relações sexuais, contato com sangue infectado e de mãe para filho. construção de uma sociedade democrática, na qual nenhuma pessoa seja submetida a quaisquer formas de discriminação, coerção e violência, em razão de suas orientações sexuais e identidades de gênero. Hoje, a ABGLT é uma rede nacional de 308 organizações afiliadas. E é a maior rede LGBTTT na América Latina. Ela é central para a promoção de políticas públicas, como o Programa Brasil sem homofobia, e de debates legislativos visando à aprovação de leis relacionadas ao tema.

Em um passado recente, as identidades sexuais pareciam definidas e naturais. Hoje, os movimentos LGBTTT exigem o reconhecimento da diversidade sexual como possibilidade da condição humana e reclama direitos a ela relacionados, além de combater todas as formas de homofobia e sexismo. Com isso, outras formas de viver a sexualidade encontraram ambiente propício para se mostrar e lutar por espaço. Além de impactos na vida cotidiana, isso também alimenta os debates acadêmicos sobre o tema.

Em sua tese de doutorado, intitulada Quem sou eu? Que lugar ocupo? - Grupos gays, educação e a construção do sujeito homossexual, Anderson Ferrari (2005, p. 98) questiona se seria possível:

[...] pensar como renovação a preocupação com a educação mais formal, sobretudo após a epidemia da AIDS, que em seu início atingiu, sobremaneira, a comunidade homossexual masculina, sendo apelidada, inclusive de "câncer gay"? Ante a exigência de se organizar contra a doença, os grupos gays reafirmaram a importância da educação como a melhor arma nessa guerra sem tréguas.

Para Anderson Ferrari (2005, p. 99), o advento da AIDS fortaleceu a preocupação dos grupos com esse modelo de homossexual a ser construído e valorizado. Ele explica que:

[...] há uma grande preocupação dos grupos com o contexto escolar e com 
o tipo de formação e informação que os adolescentes homossexuais, ou não, estavam tendo contato em tempos de AIDS. Isso parece se justificar pelas questões que estão em pauta para os grupos gays desde sua origem, como visibilidade, orgulho, respeito e cidadania, além dos adolescentes representarem a continuidade, permanência ou mesmo ruptura com o que está em discussão. Frente a essas questões, podemos dizer que os grupos pesquisados organizam suas ações de intervenção nas escolas de duas formas: através de palestras, tanto para adolescentes, quanto para os profissionais de educação e através de material de divulgação.

Por ser uma instituição social estruturante da heteronormatividade, os grupos sociais que lutam por reconhecimento de outras sexualidades irão atuar para ocupar tanto o espaço físico quanto o abstrato da escola. Isto é, os movimentos LGBTTT não apenas querem estar na escola, como também buscam interferir na lógica de construção do conhecimento, para desconstruir a naturalidade da heterossexualidade e promover o respeito à diversidade sexual.

\section{Para superar os conflitos e repensar a escola}

Sendo a escola uma das instituições que desempenham um forte controle heteronormativo, estando a heteronormatividade presente em seus discursos, silêncios e práticas, faz-se necessário repensar a lógica e desvelar os mecanismos de exclusão presentes no cotidiano escolar. Nesse sentido, Vera Candau (2012, p. 147) defende a desconstrução e reconstrução da cultura escolar:

Trata-se de promover uma educação em direitos humanos na perspectiva intercultural crítica que afete todos os atores e as dimensões do processo educativo, assim como os diferentes âmbitos em que ele se desenvolve.

Para contribuir com o debate intercultural, Marcelo Andrade (2011, p. 1101) aponta alguns fundamentos epistemológicos e éticos a partir de Karl Popper e Norberto Bobbio:

[...] de Popper, a certeza de que a verdade é sempre provisória e a aposta ética na tolerância. De Bobbio, a verdade no plural e a serenidade como a capacidade de mitigar os fardos da vida.

A respeito da tolerância, Marcelo Andrade (2009, p. 181) também nos ensina que ela deveria ser vista como um primeiro passo, e não como o objetivo final. A tolerância é um mínimo ético sem o qual não há convivência possível. Ela é a base sobre a qual políticas democráticas, currículos plurais e valores compartilhados poderão ser erguidos.

Repensar a lógica é repensar o modo de fazer, é repensar o ensino. Para ensinar de outra forma, dentro de outra perspectiva, o professor precisa de uma formação diferente. Ana Canen e Giseli Xavier (2011, p. 641) indicam-nos a necessidade de reformular a formação inicial e continuada de professores:

[...] articular tais conceitos (como diversidade, diferença, igualdade e justiça social) à formação de professores tem se tornado um desafio premente para a educação e para as instâncias envolvidas nesse processo. A formação de professores, seja ela inicial ou continuada, constitui-se como um lócus privilegiado, não só para refletir e discutir sobre essas questões, como para a criação e a implementação de proposições que possibilitem vislumbrar novos caminhos e avanços no que tange ao trato da diversidade cultural no contexto escolar.

Discutir questões de sexualidade, encarando as identidades sexuais como 
fluidas ${ }^{7}$ apesar de divergir da visão essencialista dos movimentos LGBTTT, amplia as visões e questiona a constituição dos opostos hierarquizados e os processos pelos quais uma forma de sexualidade se estabeleceu como dominante, ganhando o status de natural. Isso não implica negar as características semelhantes que permitem a associação dos indivíduos em grupos culturais. Mas implica pensar que a sexualidade não possui um caráter determinístico. Ela é construída social e historicamente. Um indivíduo transforma sua identidade sexual dependendo das experiências que vive ao longo de sua trajetória e com isso deixa de se reconhecer em determinado grupo cultural para se reconhecer em outro.

Por isso, lembramos a conceituação de pós-modernismo, pois ele privilegia a mistura, o hibridismo e a mestiçagem de culturas e de modos de vida. Pensando pelo multiculturalismo pós-moderno (CANEN, Ana, 2007, p. 93; CANEN, Ana; XAVIER, Giseli, 2011, p. 644), evitamos a certeza e as afırmações categóricas, radicalizando questionamentos lançados às formas dominantes de viver e de conceber o conhecimento, o indivíduo e a realidade. É desse ponto de vista que a forma como a sexualidade tem sido controlada e ensinada pode ser questionada.

Com ele, buscamos identificar, na própria linguagem e na construção dos discursos, as formas como as diferenças são construídas. Isso porque a visão pós-moderna, grosso modo, focaliza os processos pelos quais os discursos não só representam a realidade, mas são constitutivos e legitimadores da

7- Destacamos as contribuições da Teoria Queer (LOURO, Guacira, 2008b, p. 13): "Não há lugar de chegar, não há destino pré-fixado, o que interessa é o movimento e as mudanças que se dão ao longo do trajeto". mesma. A questão não é saber por que algo é verdadeiro, mas sim como esse algo se tornou verdadeiro. Isso significa que tal visão busca identificar expressões preconceituosas, bem como desvelar as marcas e as construções da linguagem que estejam impregnadas por aspectos identitários dominantes.

Como indica-nos Anderson Ferrari (2014, p. 106), a escola:

[...] por ser o lugar por excelência de conhecimento, não é o espaço do senso comum, mesmo que ele insista em aparecer pelas falas dos alunos e alunas. A escola é o local de problematização do senso comum, do que não nos assusta mais porque naturalizamos. E dizer das homossexualidades é dizer desse senso comum, dessa forma de conhecer que organiza o social, que invade as escolas e que constrói sujeitos. Assumir a postura de problematização é mais do que olhar para o que está nas salas de aula, é questionar a forma de conhecer, é dar um passo atrás para olhar de outra forma.

Portanto, e em forte alinhamento com Anderson Ferrari, acreditamos estar na problematização, no questionamento, na habilidade do pensar diferente, o espaço propício para a desmistificação de identidades e para a superação de preconceitos e discriminações. É neste espaço que a tolerância floresce e a diferença se valoriza. É resgatando a problematização que poderemos pensar em um novo formato escolar, no qual as verdades são abaladas, mas também onde é possível pensar, refletir e se colocar no lugar do outro, onde é possivel ser diferente. 


\section{Referências}

ABGLT. Associação Brasileira de Lésbicas, Gays, Bissexuais, Travestis e Transexuais. Disponível em: <http://www.abglt.org.br/port/ index.php>. Acesso em: 08 abr. 2015.

ANDRADE, Marcelo. Sobre pluralismo, verdade e tolerância: diálogos epistemológicos e éticos para uma educação intercultural. Educação e Sociedade, Campinas, v. 32, n. 117, p. 1087-1103, 2011.

ANDADE, Marcelo. Tolerar é pouco? Pluralismo, mínimos éticos e práticas pedagógicas. Petrópolis: DP et Alii, 2009.

ALVES, José Augusto. Os direitos humanos na pós-modernidade. São Paulo: Perspectiva, 2005.

AMERICAN PSYCHIATRIC ASSOCIATION - APA. Mental health disparities: lesbian/gay/bisexual/transgender. 2013. Disponível em: $<$ http://www.psychiatry.org >. Acesso em: 28 out. 2014.

ARROYO, Miguel. Políticas educacionais e desigualdades: à procura de novos significados. Educação e Sociedade, Campinas, v. 31 , n. 113, p. 1381-1416, 2010.

BENTO, Berenice. Corpos e próteses: dos limites discursivos do dimorfismo. In: SEMINÁRIO INTERNACIONAL FAZENDO GÊNERO: GÊNERO E PRECONCEITOS, 7., 2006, Florianópolis. Anais... Florianópolis: UFSC, 2006. Disponível em: <http://www. fazendogenero7.ufsc.br>. Acesso em: 20 jun. 2010.

BERND, Zilá. Estudos canadenses e transculturalismos. In: ALMEIDA, Sandra Regina Goulart (Org.). Perspectivas transnacionais $=$ Perspectives transnationales $=$ Transnational perspectives. Belo Horizonte: ABECAN/FALE/UFMG, 2005. p. 145-159.

BORRILLO, Daniel. Homofobia: história e crítica de um preconceito. Belo Horizonte: Autêntica, 2010.

BRASIL. Câmara promove enquete sobre conceito de família. Diário Oficial da União, 2013. Disponível em: <http://www2. camara.leg.br>. Acesso em: 02 nov. 2014.

BRASIL. Supremo reconhece união homoafetiva. Diário Oficial da União, 2011. Disponivel em: <http://www.stf.jus.br>. Acesso em 03 nov. 2014.

CANDAU, Vera. Diferenças culturais, interculturalidade e educação em direitos humanos. Educação e Sociedade, Campinas, v. 33, n. 118, p. 235-250, 2012.

CANDAU, Vera. Direitos humanos, educação e interculturalidade: as tensões entre igualdade e diferença. In: CANDAU, Vera (Org.). Educação intercultural na América Latina: entre concepções, tensões e propostas. Rio de Janeiro: 7Letras, 2009. p. 154-173.

CANEN, Ana. 0 multiculturalismo e seus dilemas: implicações na educação. Comunicação e Política, Rio de Janeiro, v. 25, n. 2, p. 91-107, 2007.

CANEN, Ana; XAVIER, Giseli. Formação continuada de professores para a diversidade cultural: ênfases, silêncios e perspectivas. Revista Brasileira de Educação, Rio de Janeiro, v. 16, n. 48, p. 641-813, 2011.

CID. Classificação Internacional de Doenças. Organização Mundial das Nações Unidas, 2006. Disponível em: <http://www.datasus. gov.br/cid10 >. Acesso em: 10 nov. 2014.

CUCHE, Denys. A noção de cultura nas ciências sociais. Bauru: Edusc, 2002.

ERIKSEN, Thomas. Small places, large issues: an introduction to social and cultural anthropology. Chicago: Pluto Press, 1995.

FERRARI, Anderson. Experiência homossexual no contexto escolar. Educar em Revista. Curitiba: Editora UFPR, Edição Especial n. 1, p. 101-116. 2014.

FERRARI, Anderson. Quem sou eu? Que lugar ocupo? Grupos gays, educação e a construção do sujeito homossexual. 2005. Tese (Doutorado). Universidade Estadual de Campinas, Campinas, 2005.

FOUCAULT, Michel. História da sexualidade I: a vontade de saber. Rio de Janeiro: Graal, 2009.

FOUCAULT, Michel. Microfísica do poder. Rio de Janeiro: Graal, 2000.

FOUCAULT, Michel. Vigiar e punir: nascimento na prisão. Petrópolis: Vozes, 2008. 
FURLANI, Jimena. Mitos e tabus da sexualidade humana: subsídios ao trabalho em educação sexual. Belo Horizonte: Autêntica, 2007. HALL, Stuart. A identidade cultural na pós-modernidade. Rio de Janeiro: DP\&A, 2001.

HALL, Stuart. Quem precisa de identidade? In: SILVA, Tomaz Tadeu; HALL, Stuart; WOODWARD, Kathryn. Identidade e diferença: a perspectiva dos estudos culturais. Petrópolis: Vozes, 2010. p. 103-133.

HEILBORN, Luiza. Gênero e hierarquia: a costela de Adão revisitada. Revista de Estudos Feministas, Florianópolis, v. 1, n. 1, p. 50-82, 1993.

JAPIASSÚ, Hilton; MARCONDES, Danilo. Dicionário básico de filosofia. Rio de Janeiro: Zahar, 2006.

JOHNSON, Allan. Dicionário de sociologia: guia prático da linguagem sociológica. Rio de Janeiro: Jorge Zahar, 1997.

KHALEELI, Homa. Hijra: India's third gender claims its place in law. 2014. Disponível em: <http://www.theguardian.com/ society/2014/apr/16>. Acesso em: 24 out. 2014.

LOURO, Guacira. Pedagogias da sexualidade. In: LOURO, Guacira (Org.). 0 corpo educado: pedagogias da sexualidade. Belo Horizonte: Autêntica, 2010. p. 07-34.

LOURO, Guacira. Gênero, sexualidade e educação: uma perspectiva pós-estruturalista. Petrópolis: Vozes, 2008a.

LOURO, Guacira. Um corpo estranho: ensaios sobre sexualidade e teoria queer. Belo Horizonte: Autêntica, 2008b.

ONU. Até 86 milhões de meninas poderão sofrer com mutilação genital feminina até 2030, alerta ONU. 2014. Disponível em: <http://www.onu.org.br/>. Acesso em: 15 out. 2014.

ONU. Declaração Universal dos Direitos Humanos: assembleia geral das Nações Unidas. 1948. Disponível em: <http://unesdoc. unesco.org/images/0013/001394/139423por.pdf>. Acesso em: 25 out. 2014.

PRADO, Marco Aurélio; MACHADO, Frederico. Preconceito contra homossexualidades: a hierarquia da invisibilidade. São Paulo: Cortez, 2008.

SCOTT, Joan. Gênero: uma categoria útil de análise histórica. Educação e Realidade, Porto Alegre, v. 20, n. 2, p. 71-99, 1995.

SPINDLER, G. D. The transmission of culture. In: SPINDLER, G. D. (Ed.) Education and cultural process: anthropological approaches. Long Grove: Waveland Press, 1987. p. 275-309.

VATICANO. Sexualidade humana: verdade e significado. Orientações educativas em família. 1995. Disponível em: <http://www. vatican.va/roman_curia/>. Acesso em: 02 nov. 2014.

Recebido em: 08.04.2015

Aprovado em: 27.05.2015

Raquel Pinhoé doutoranda em educação (PPGE/PUC-Rio), integrante do Grupo de Estudos sobre Cotidiano, Educação e Cultura (GECEC) e bolsista CAPES.

Rachel Pulcino é doutoranda em educação (PPGE/PUC-Rio), integrante do Grupo de Estudos sobre Cotidiano, Educação e Cultura (GECEC) e bolsista Capes. 
No artigo "Desfazendo os nós heteronormativos da escola: contribuições dos estudos culturais e dos movimentos LGBTTT" DOI: http://dx.doi.org/10.1590/S1517-97022016148298 publicado no periódico Educação e Pesquisa: Revista da Faculdade de Educação da USP, v. 42, n. 3, 2016.

Página 680

\section{Onde se lia}

Raquel Pinto é doutoranda em educação (PPGE/PUC-Rio), integrante do Grupo de Estudos sobre Cotidiano, Educação e Cultura (GECEC) e bolsista CAPES.

Raquel Pulcino é doutoranda em educação (PPGE/PUC-Rio), integrante do Grupo de Estudos sobre Cotidiano, Educação e Cultura (GECEC) e bolsista Capes.

\section{Leia-se}

Raquel Pinho é doutoranda em educação (PPGE/PUC-Rio), integrante do Grupo de Estudos sobre Cotidiano, Educação e Cultura (GECEC) e bolsista CAPES.

Rachel Pulcino é doutoranda em educação (PPGE/PUC-Rio), integrante do Grupo de Estudos sobre Cotidiano, Educação e Cultura (GECEC) e bolsista Capes. 